\title{
Influence of environment on the corrosion of glass-metal connections
}

\author{
Barbara Szala $\cdot$ Elżbieta Greiner-Wronowa $\cdot$ \\ Paolo Piccardo • Monika Kwaśniak-Kominek • \\ Tomasz Bajda
}

Received: 27 January 2014/ Accepted: 1 May 2014/Published online: 27 May 2014

(C) The Author(s) 2014. This article is published with open access at Springerlink.com

\begin{abstract}
Glass sensors' of the eighteenth century Backer glass and the sixteenth century enamel from Limoges have been chosen for a series of experiments. Combinations of these materials with different base materials such as copper and bronze has been investigated. To create surface changes on the 'glass sensor', a corrosion process was induced in a controlled environment. A variety of corrosive agents such as hydrochloric acid, sulfuric acid, water and formaldehyde were used. The sample immersed in the corrosive solution was exposed alternately to light and high temperature for a total of 38 weeks. During this period, macroscopic and microscopic observations were made and series of tests such as SEM/EDS and Raman spectroscopy were performed on the surface of the samples. ICP-MS methods were used to determine the change in the chemical composition of the solutions where the samples had corroded. The primary aim of this study was to identify the impact of a number of external corrosive variables such as temperature, humidity and local environment to identify the most damaging environments for glass-metal objects. The obtained results showed the chemical and physical phenomena acting on the surface of
\end{abstract}

B. Szala $(\bowtie) \cdot$ M. Kwaśniak-Kominek · T. Bajda

Faculty of Geology, Geophysics and Environmental Protection, AGH University of Science and Technology in Kraków,

30 Mickiewicza Av., 30-059 Kraków, Poland

e-mail: bszala@geol.agh.edu.pl

E. Greiner-Wronowa

Faculty of Materials Science and Ceramics, AGH University of Science and Technology in Kraków, 30 Mickiewicza Av., 30-059 Kraków, Poland

P. Piccardo

LMM, DCCI, Università degli Studi di Genova,

via Dodecaneso 31, 16146 Genoa, Italy the glass, metal or in the place of their joints. Information obtained on this study was used to explain the influence of the environment on the surface of glass-metal materials. Results can be used in the design of conservation work as well as for sustainable conservation.

\section{Introduction}

Historical objects represent material proof of human activity and are the testimony of a bygone era. Each artifact brings not only historical value, but also carries artistic and scientific merit. Therefore, they require special care and personal attention to maintain their condition. Corrosive agents appear on the material's surface and over time objects can be destroyed [1]. Physical and chemical changes due to mechanic deterioration as well as chemical reactions between glass elements and its surrounding environment cause deterioration of the objects [2,3]. There are many examples of objects where glass and metal are connected for both esthetics and functionality. A significant group of historical glass-metal objects used in this research were enamels from Limoges and the eighteenth century Backer glass.

The painted enamels, produced during the Renaissance period in Limoges, are unique and extraordinary due to their figurative composition and creative achievements. Their uniqueness is also apparent given the technological knowledge about melting and the expansion properties of the glass flux that the workshops had $[4,5]$. The enamels can show signs of deterioration, induced through the chemical composition of the enamels, humidity, temperature and atmospheric pollution [6]. These implications cause an irreversible loss of the material's mass and changes in color and the transparency of the glass [7]. The 
Renaissance brought, especially to the royal court, not only richly decorated enamels, paintings and furniture but also glass crockery and cups which were often fitted with metal parts. The mechanism of corrosion of glass objects from that period is well known. In previous studies, glass diseases such as crizzling crying glass, weathering and glass crystallization are documented [8-10]. Also, the corrosion of metal objects was frequently described in the literature $[11,12]$. Corrosion of stained glass and enamel has been described, largely focusing on the corrosion of individual components [13]. However, what is still missing is information on the mechanism of corrosion of glass-to-metal objects and the impact the environment has on the crystallizing on the surface products.

There are many corrosion catalysts, depending on the material causing the deterioration of the surface. Metals can be the subject of two kinds of corrosion: chemical or electrochemical (galvanic). Glass corrosion is primarily the result of hydrolysis, leaching, weathering and progressive crystallization-which is a natural occurrence through the passage of time [14]. Finally, corrosion of objects containing both metal and glass is caused by reactions occurring first on the weakest material-metal and later on in the connecting areas of metal to glass. Identifying reactions on the surface of historical object is a subject that interests many researchers. However, using original materials is irrational as during the test a lot of materials may be destroyed.

The biggest limitation and challenge are the amount of samples. In previous studies, non-destructive methods in historical research are described $[15,16]$. However, they are still unable to say with absolute certainty that the analysis which uses light rays, radiation, laser and electron excitation does not cause any damage, especially in the future. Therefore, some pre-prepared replica glass had to be manufactured. The so-called "glass-sensor method" allowed one to produce an unlimited amount of material for experiments of induced corrosion processes as well as other tests without damaging any historical—perhaps valuable—original pieces [17].

The aim of this study was to determine the most aggressive environment for a group of glass-metal historical objects. 'Glass sensors', which were the subject of a series of aggressive process, were used for this study. Corrosion changes on the surface of the material were diagnosed and the mechanisms of corrosion of glass-to-metal objects were determined. Results can be used in the design of conservation work as well as for sustainable conservation-providing optimal storage conditions for glass-metal objects.

\section{Materials and methods}

The glass sensor used in this research was created based on the chemical composition of an eighteenth century glass
Table 1 Composition (wt \%) of compounds used to prepare the blue enamel, the Limoges enamel reproduction

\begin{tabular}{lcclll}
\hline Compound & $\begin{array}{l}\text { Beaker } \\
\text { glass }\end{array}$ & Enamel & Compound & $\begin{array}{l}\text { Beaker } \\
\text { glass }\end{array}$ & Enamel \\
\hline $\mathrm{SiO}_{2}$ & 73.94 & 43.26 & $\mathrm{Fe}_{2} \mathrm{O}_{3}$ & 0.06 & 0.13 \\
$\mathrm{Al}_{2} \mathrm{O}_{3}$ & 0.07 & & $\mathrm{CoO}$ & & 0.24 \\
$\mathrm{CaO}$ & 9.26 & 1.90 & $\mathrm{MbO}_{2}$ & & 0.39 \\
$\mathrm{MgO}$ & 0.59 & & $\mathrm{CuO}$ & & 1.36 \\
$\mathrm{BaO}$ & 0.14 & 0.75 & $\mathrm{ZnO}$ & & 0.06 \\
$\mathrm{~K}_{2} \mathrm{O}$ & 14.28 & 9.73 & $\mathrm{~B}_{2} \mathrm{O}_{3}$ & 0.65 & \\
$\mathrm{Na}_{2} \mathrm{O}$ & 0.84 & 16.68 & $\mathrm{TiO}$ & & 0.1 \\
$\mathrm{PbO}$ & 0.07 & 25.46 & $\mathrm{NiO}$ & & 0.04 \\
$\mathrm{MnO}$ & 0.1 & & & & \\
\hline
\end{tabular}

beaker (Table 1). This sensor has the same chemical composition as an original antique glass with comparable chemical and physical properties, as well as similar reactive qualities. Glass with a high alkali content $\left(\mathrm{Na}_{2-}\right.$ $\mathrm{O}+\mathrm{K}_{2} \mathrm{O}=15.22 \%$ wt.), with the addition of lead oxide is technically soft and called technological long glass. Shapes are easily made during an extended period when the glass has a viscosity suitable for molding by hand.

To prepare samples of enamel on copperplate, a known oxide composition of the original enamel from Limoges was used (Table 1). The blue enamel was put on the copper plate and then thermally treated. The prepared enamel has a high content of lead oxide and a low content of silica. Such glass is characterized by a high refractive index and a high density. Furthermore, the typical composition of the oxide mass of the blue coloring has been applied, with the coexistence of copper oxide $(\mathrm{CuO})$, cobalt oxide $(\mathrm{CoO})$, and nickel oxide $(\mathrm{NiO})$.

Samples of the eighteenth century glass sensors were adjoined to pieces of metal. The next step was to place the samples consisting of glass joined with metal into various corrosion catalytic environments:

- Sample A: glass sensor + copper band, immersed in a $0.1 \mathrm{M}$ hydrochloric acid $\mathrm{HCl}$;

- Sample B: glass sensor + copper band, immersed in water;

- Sample C: glass sensor + brass band, immersed in water;

- Sample D: glass sensor + copper band, immersed in $0.01 \mathrm{M}$ hydrochloric acid $\mathrm{HCl}$;

- Sample E: enamel placed on the copper in the form of two drops, immersed in $20 \%$ formaldehyde (HCHO);

- Sample F: glass sensor + brass band, immersed in a $0.5 \mathrm{M}$ solution of sulfuric acid (VI) $\left(\mathrm{H}_{2} \mathrm{SO}_{4}\right)$.

The reconstituted material as an example of glass-metal objects was subjected to corrosion induced over a period of 
Fig. 1 Graphical scheme of the corrosion-induced processes

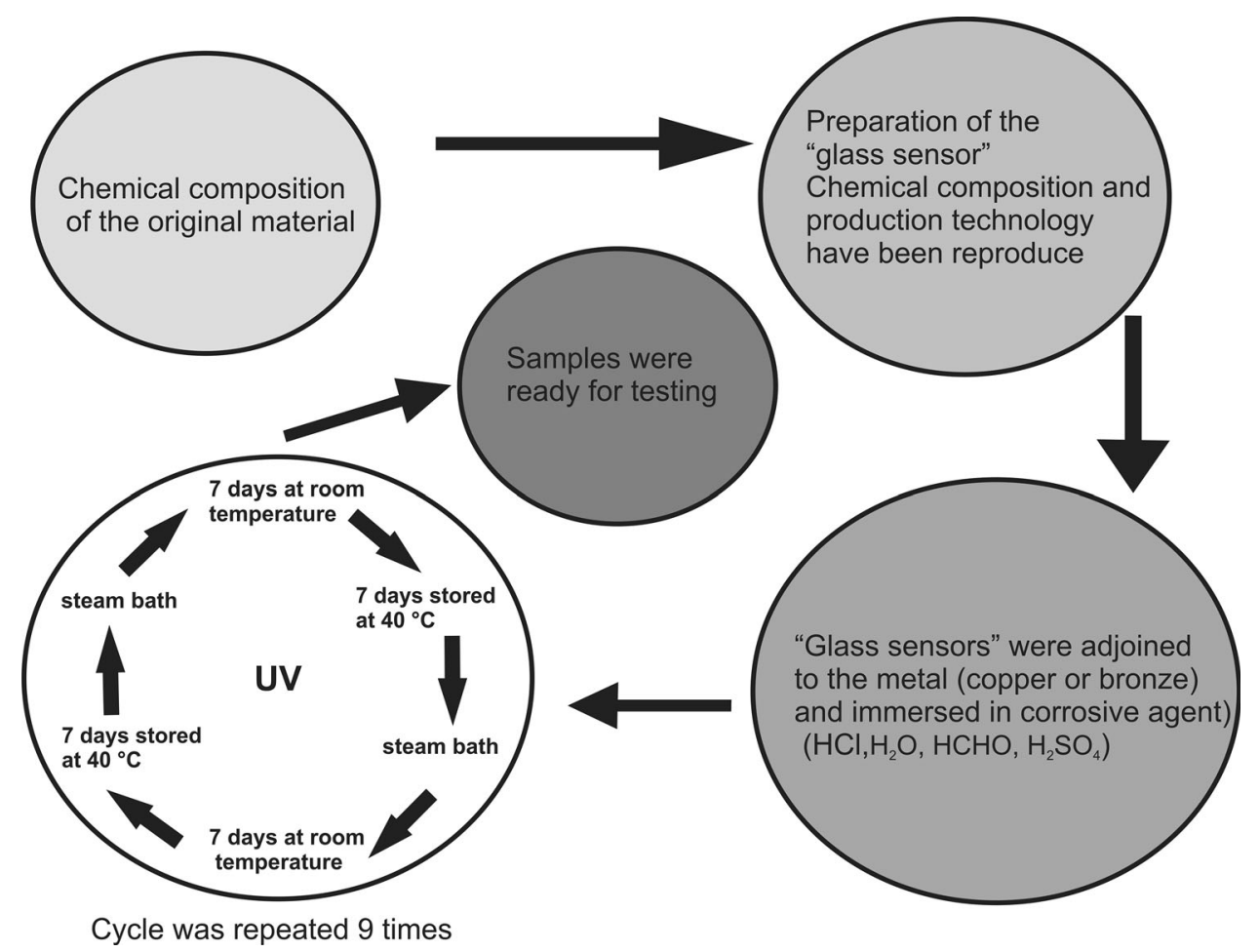

38 weeks. To accelerate the corrosion of the sample, the solutions were periodically subjected to an elevated temperature and strong light. Initially, the sample was boiled in a steam bath (4 times per hour) and in successive stages and the solutions stored at room temperature. Every other week, after $168 \mathrm{~h}$, they were kept at $40{ }^{\circ} \mathrm{C}$ (Fig. 1.).

To identify the most corroded points, a stereoscopic observation was made using Leica Wild M8 stereoscope. After the initial diagnosis of the areas affected by corrosion, observations were made using a microscope metallographic MET 3. Examination by SEM/EDS was performed with a scanning electron microscope, Carl Zeiss AG-EVO 40 Series. This helped to identify the quality and quantity of elements produced during experimentation on the glass and metal surface, as well as obtaining the chemical composition of both elements. The intention was also to observe the crystallized surface morphology and corrosion products on the surfaces of objects [18]. After 38 weeks of this induced corrosion, the sample's corrosion was specified through atomic emission spectroscopy_-identifying the composition of the samples (ICP-MS DRCII by Perkin-Elmer). For samples $\mathrm{B}, \mathrm{D}, \mathrm{E}$ and $\mathrm{F}$, further analysis of the phase composition was performed using Raman spectroscopy (Leica Renishow DMLM). This apparatus uses two lasers at 514 and $785 \mathrm{~nm}$. A single beam spectrometer was used, with a camera connected to the confocal microscope and the imaging filter set to dispersive Raman imaging.

\section{Results and discussion}

\subsection{Stereoscope}

The preliminary diagnosis indicated several significant points on the samples which were later investigated in more depth (Fig. 2). In the case samples A it can be noted that the grinding surface of the glass is much more corroded than the broken surface. Glass of a given composition (eighteenth century original glass) is presented as a glass with numerous blisters. These blisters can indeed accelerate the corrosion process. To observe the changes in sample B, a metal band was removed. The precipitate was clearly visible between the metal and the glass in the form of a brown product. Observations also indicated a considerably large amount of fogging in the glass. On sample C, a white crystallized product appeared on the surface of both the glass and metal. These places were subject to further in-depth studies. Sample D was of significant interest when subjected to corrosion. The copper band around the glass dissolved in $0.1 \mathrm{M} \mathrm{HCl}$, and the resulting reaction formed a green crystalline corrosion on the entire surface of the glass and metal. Also, the acid solution discolored and the reaction of the chloride ion with copper resulted in the precipitation of the product being crystallized over the entire surface of the beaker. Sample E proved most complicated as the prior literature on the problem of corrosion glass-metal objects in formaldehyde is in short supply. It should be noted that 

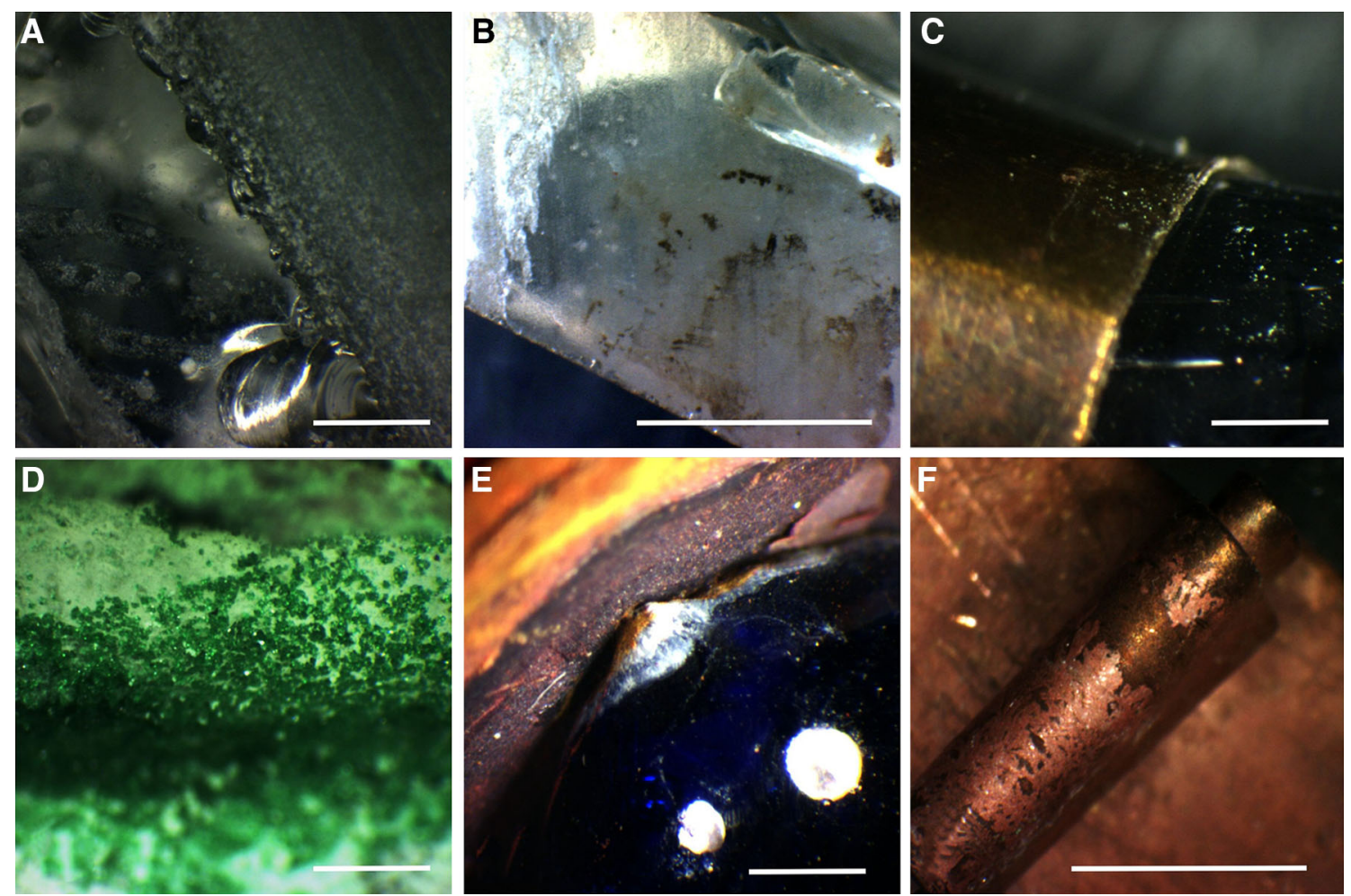

Fig. 2 Microphotographs of the samples A-F after administering induced corrosion of the samples in aqueous solutions. a $0.1 \mathrm{M} \mathrm{HCl}, \mathbf{b} \mathrm{H}_{2} \mathrm{O}$, c $\mathrm{H}_{2} \mathrm{O}$, d $0.01 \mathrm{M} \mathrm{HCl}$, e $20 \% \mathrm{HCHO}$, f $0.5 \mathrm{M} \mathrm{H}_{2} \mathrm{SO}_{4}$. Wild Leica M8 Stereoscope. Scalebar $20 \mu \mathrm{m}$

sample E consisted of two materials which exist together. Their corrosion process must take into account some synergetic reactions. Their analysis was very complicated because of many chain reactions which are hard to distinguish from each other in the organic media. Such a sample must almost certainly be multiplied and tested separately after a defined period of time. Moreover, a change in color can be seen on the metal surrounding the glass. Corrosion products on both materials have been easily observed as a result of the build-up of material between the enamel and the metal, caused partly by the detachment of enamel from the base. In the case of sample B (glass sensor immersed in a solution of sulfuric acid), the corrosion of the glass was not evident during stereoscopic observation. Attention was attracted by the corrosion of the metal band (Fig. 2). There were clearly visible areas of corrosion and color change in the metal band, presumably the result of the oxidation reaction.

\subsection{Metallographic microscope}

Microscopic observations were carried out on the surface of cross-sectional layers of specially prepared samples of enamel on copperplate sample (Fig. 3). Observations showed an increase of $20 \mu \mathrm{m}$, enabling the initial diagnosis of the resulting layers of corrosion. This proved an efficient and effective way to provide information on the thickness, color and structure of the observed layers [19]. Photos from a metallographic microscope allowed for further planning and the subsequent use of SEM/EDS and RS-mitigating the need for analysis of the entire sample's surface. Photographs show the extensive changes arising from the combination of metal to glass. Red corrosion products between the materials are vividly shown by their penetration into the structure of the enamel. The red color indicates that the corrosion product is a copper oxide (I) $\mathrm{Cu}_{2} \mathrm{O}$-product of oxidation of copper. The corrosion layer is thicker closer to the glass part (enamel) (Fig. 3 a, b). This suggests that the mechanisms of the corrosion accelerate in places where the ions from the solution react with components leaching from the glass. Thickness of the corrosion layer is as much as $400 \mu \mathrm{m}$. Photographs taken suggest possible oxidation reactions (metal to oxide), drawing attention to the growing area of corrosion and the buildup of crystallites between the copper and enamel. As a result of this, one of the two drops of enamel lost its adhesion to the substrate and disconnected.

\subsection{Scanning electron microscope}

Due to the high concentration of the hydrochloric acid $(0.1 \mathrm{M})$, the metal element (copper) in the sample A was 

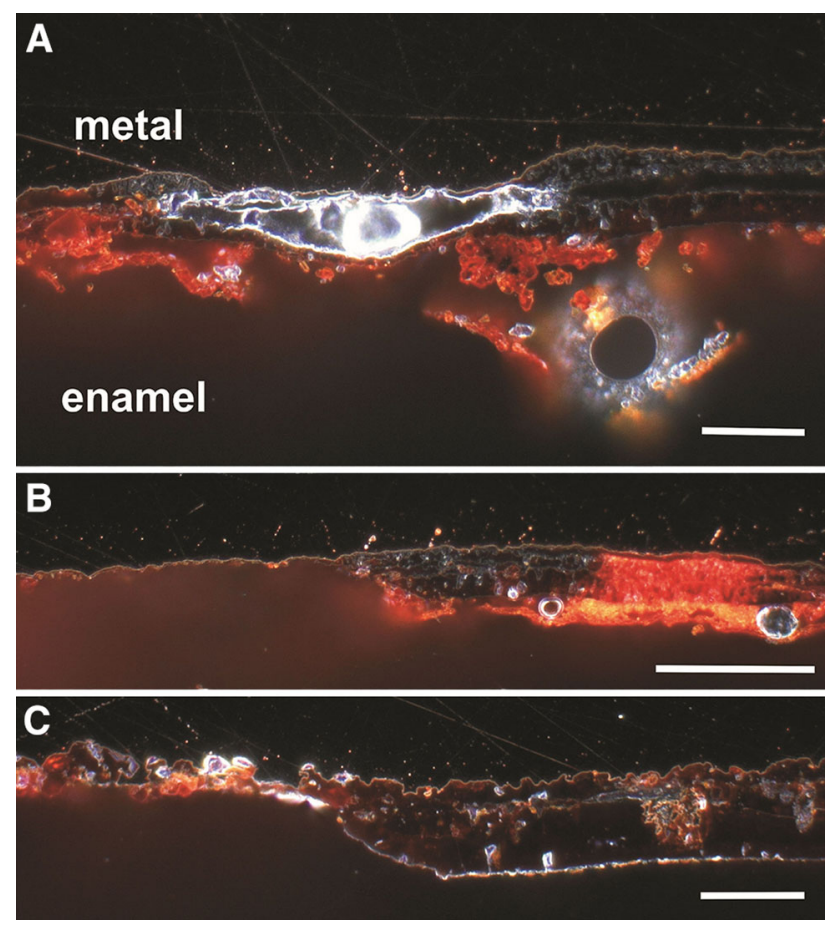

Fig. 3 Metallographic microphotographs of sample E (enamel on copperplate, the corrosion induced by $20 \%$ formaldehyde solution). Pitting corrosion and blistering in enamel are visible. a Corrosion of enamel-copperplate connection. b Changes of corrosion layer thickness depending on the distance from the enamel. $\mathbf{c}$ The differences in the thickness of corrosion buildups. Scalebar $250 \mu \mathrm{m}$

completely dissolved. Therefore, further studies were based on the analysis of sample D (a lower concentration of $0.01 \mathrm{M} \mathrm{HCl})$. Only the acid solution $(0.1 \mathrm{M} \mathrm{HCl}$ from sample A), for which the metal band had dissolved, has been tested by ICP-MS (next paragraph). In the case of sample B, the metal surface in contact with the glass shows the corrosion products crystallized in the form of tetrahedrons (Fig. 4). The semi-quantitative chemical analyses by EDS on spots displayed the largest amount of copper and oxygen (oxidation products) (Table 2). What was also an interesting find, was the presence of chlorine and sulfur, most likely originating from the surrounding area.

On sample C, corrosive spherical-shaped lesions were observed (Fig. 4). The analysis made apparent the precipitate formed is a compound of copper $(\mathrm{Cu})$, oxygen $(\mathrm{O})$, zinc ( $\mathrm{Zn}$ ), and sodium (Na) (Table 2). Relatively high concentrations of sodium (Na) may be the result of hydrolysis and hydration, which eventually lead to the leaching of alkali from the glass.

For sample D, 13 measurements in total were made. Most of the analysis showed that the corrosion product is a compound of copper $(\mathrm{Cu})$, oxygen $(\mathrm{O})$ and chlorine $(\mathrm{Cl})$. Also noted was the presence of carbon (C) at a concentration of $<7 \%$ by weight. It is very difficult to describe the shape of the crystallites (Table 2).
Sample E consisted of blue enamel applied to a substrate made of brass, kept in a $20 \%$ solution of formaldehyde HCHO (Fig. 5). At the beginning, corrosion of the metal substrate away from the application site of enamel was analyzed. Then, the qualitative composition of the products of corrosion occurring around the enamel drop was determined (corrosion of metal close to enamel).

The obtained results indicated a difference in the composition of the enamel-metal corrosion layer (Fig. 5), as well as other corroded areas. The three elements in highest concentration were carbon (C: $7.8 \%$ wt.), oxygen (O: $11.2 \%$ by wt.) and copper (Cu: $85.1 \%$ by wt.) (Table 2 ). The chlorine (Cl: $0.5 \%$ by wt.) arises from the surrounding area before preparation and being immersed in a $20 \%$ solution of formaldehyde. The closer to the enamel, the more prevalent elements originating from the glass were carbon (C: $6.5 \%$ by wt.), oxygen (O: $10.11 \%$ by wt.) and copper (Cu: $82.26 \%$ by wt.), and also detected: Silicon (Si: $0.3 \mathrm{wt} \%$.) and lead (Pb: $0.8 \%$ by wt.). Finally, an analysis was conducted on the surface of the enamel (\%wt.): C-8,5; O-34,9; Al-0,2; Si-16,3; Cl-0,3; K-0,7; Ca-0,7; Cu-6,6; Pb12,0 . It could be assumed that the relatively high concentration of copper is the result of corrosion phenomena occurring at the border of enamel-to-metal, and is derived from the glass as one of the coloring oxides.

For sample F, a number of analytical tests were performed. Corrosive changes in the glass (strongly attached to the metal), and metal (without glass coating) were relatively minor. Corrosion is clearly visible on the surface of metal touching the glass-evident in the crystallized products displayed (Fig. 4). EDS analyses exhibited silicon, aluminum and potassium, all cations derived from the composition of the enamel (Table 2).

\subsection{Inductively coupled plasma mass spectrometry (ICP-MS)}

The results confirm the intensity of the corrosion occurring on the samples in different solutions. Table 3 indicates that the samples stored in water were moderately active ion exchanges. Metallic elements were derived from metal bands attached to the glass. The presence of copper $(\mathrm{Cu}=14 \mathrm{mg} / \mathrm{L})$ was observed in the solution of sample B (glass sensor + copper band). The presence of zinc $(\mathrm{Zn}=11.5 \mathrm{mg} / \mathrm{L})$ was noted in the solution of sample $\mathrm{C}$ (glass sensor + brass band). Furthermore, in samples B and C potassium was detected (respectively, 6.4 and $5.5 \mathrm{mg} / \mathrm{L}$ ), this indicates that the processes of aqueous hydration, hydrolysis and ion exchange in glass have occurred. An acidic environment is yet more aggressive - causing many more chemical reactions. Either in solution $\mathrm{A}, \mathrm{D}$ and $\mathrm{F}$, attention was paid to the high concentration of calcium (respectively, $\mathrm{Ca}_{\left(\mathrm{A}^{\prime}\right)}=24.7, \mathrm{Ca}_{(\mathrm{D})}=47.1$, $\left.\mathrm{Ca}_{(\mathrm{F})}=15.1(\mathrm{mg} / \mathrm{L})\right)$. It can, therefore, be claimed that the 
Fig. 4 SEM imagine of corrosion products formed between glass and metal for samples B, C, D, F. a Sample B, corrosion in water; b Sample C, corrosion in water; c Sample D, corrosion in $0.01 \mathrm{M} \mathrm{HCl}$;

d Sample F, corrosion in $0.5 \mathrm{M}$ $\mathrm{H}_{2} \mathrm{SO}_{4}$
Table 2 Elemental

composition of samples (SEMEDS). Carl Zeiss AG-EVO 40 Series
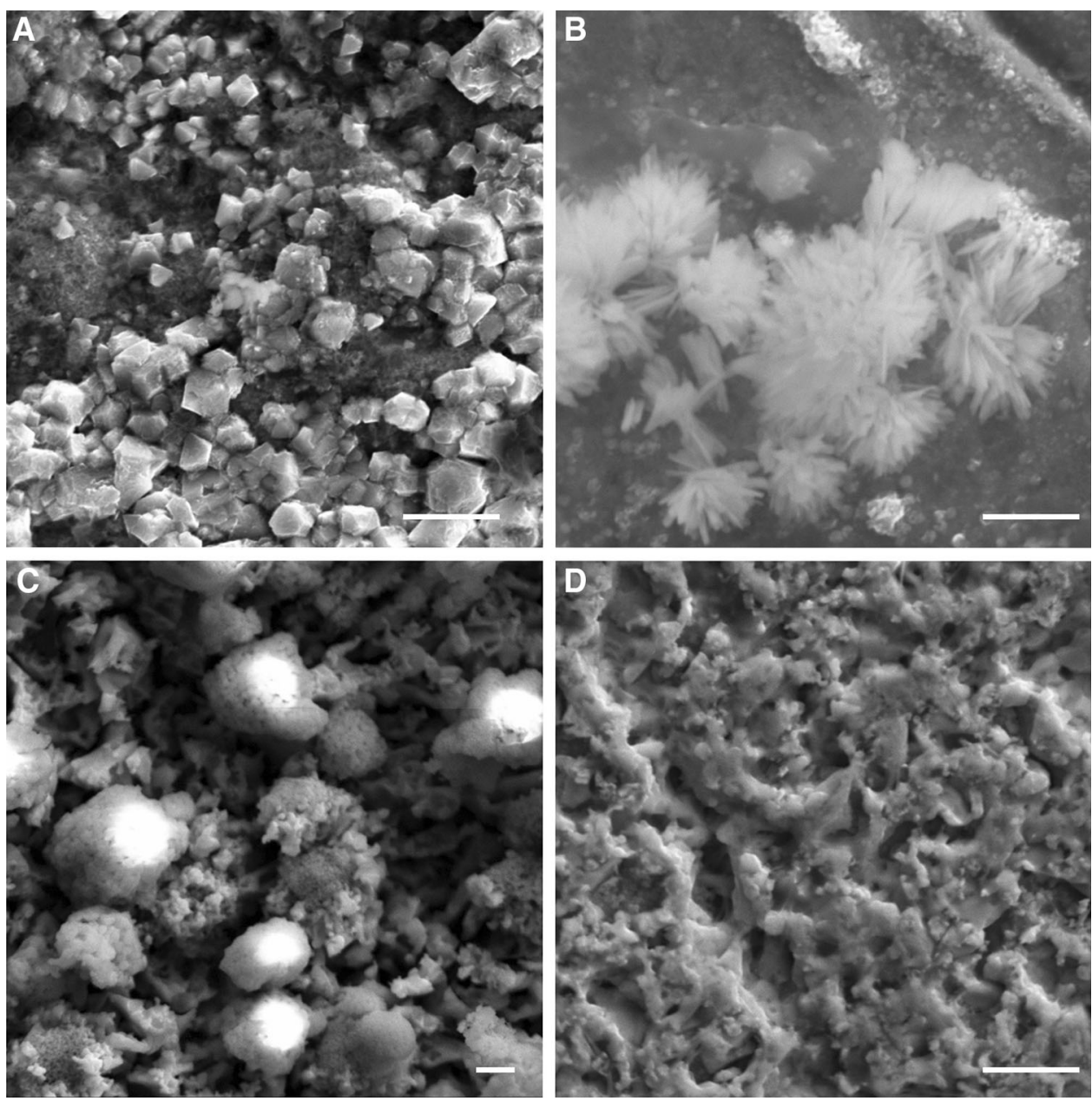

\begin{tabular}{|c|c|c|c|c|c|c|c|c|c|c|}
\hline \multirow{2}{*}{$\begin{array}{l}\text { Element } \\
\text { (wt\%) }\end{array}$} & \multicolumn{10}{|c|}{ Sample } \\
\hline & $\begin{array}{l}\text { B } \\
\text { Glass } \\
\text { side }\end{array}$ & $\begin{array}{l}\text { B } \\
\text { Metal }\end{array}$ & $\begin{array}{l}\text { C } \\
\text { Glass } \\
\text { side }\end{array}$ & $\begin{array}{l}\text { C } \\
\text { Metal }\end{array}$ & $\begin{array}{l}\text { D } \\
\text { Powder }\end{array}$ & $\begin{array}{l}\text { E Glass } \\
\text { (center) }\end{array}$ & $\begin{array}{l}\text { E } \\
\text { Glass } \\
\text { (rim) }\end{array}$ & $\begin{array}{l}\text { E Glass- } \\
\text { metal } \\
\text { border }\end{array}$ & $\begin{array}{l}\text { F } \\
\text { Glass } \\
\text { side }\end{array}$ & $\begin{array}{l}\text { F } \\
\text { Metal }\end{array}$ \\
\hline $\mathrm{Cu}$ & 83.20 & 82.81 & 18.47 & 72.58 & 59.83 & 46.98 & 6.63 & 32.15 & 77.67 & 97.35 \\
\hline $\mathrm{Zn}$ & & & 31.56 & 5.74 & & & & & 1.00 & \\
\hline $\mathrm{Pb}$ & & & & & & 7.52 & 12.25 & 4.07 & & \\
\hline $\mathrm{O}$ & 5.89 & 15.28 & 26.33 & 13.66 & 21.98 & 13.09 & 34.93 & 32.47 & 6.55 & \\
\hline $\mathrm{C}$ & & & 20.09 & & 4.43 & 1.64 & 8.53 & 4.03 & 9.27 & 2.72 \\
\hline $\mathrm{Cl}$ & 0.56 & 1.98 & & & 19.51 & 0.42 & 0.32 & & & \\
\hline S & 0.37 & & 6.51 & & & & & & & \\
\hline $\mathrm{Si}$ & & & 0.59 & & & 9.92 & 16.33 & 22.96 & 2.97 & \\
\hline $\mathrm{Al}$ & & & & & & & 0.21 & 0.24 & 1.36 & 0.35 \\
\hline $\mathrm{Ca}$ & & & & & & 0.25 & 0.74 & 0.31 & & \\
\hline $\mathrm{K}$ & & & & & & & 0.71 & & 0.65 & \\
\hline
\end{tabular}

exchange of alkalis are cations from glass with ions from the solution. This is confirmed by the measurable concentration of sodium and potassium. Structure-building elements of glass are detected in solution at high concentrations. This demonstrates the glass-metal corrosion in acidic solutions. Metal ties are also dissolved at low pH levels. High concentrations of all the elements (from the vitreous-enamel material as well as metal base) in $20 \%$ formaldehyde solution were 
Fig. 5 Sample E: cross-section of researched areas (enamel applied to the base metal) and SEM/EDS analysis of enamel application site- corrosion layer. a Visible various areas of corrosion, scalebar $1 \mathrm{~mm}$, b The boundary between enamel and copperplate, scalebar $50 \mu \mathrm{m}$. Carl Zeiss AG-EVO 40
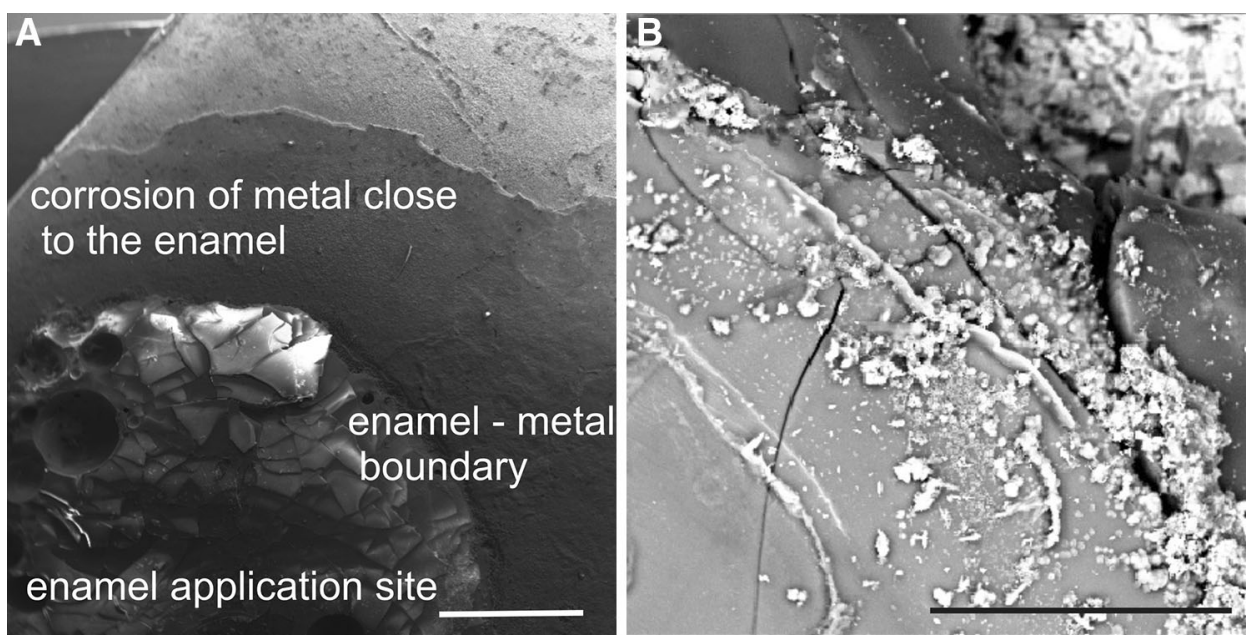

Table 3 Elemental composition of solutions after experiments

\begin{tabular}{lllllll}
\hline Element & \multicolumn{6}{l}{ Concentration $(\mathrm{mg} / \mathrm{L})$} \\
\cline { 2 - 7 } & $\mathrm{A}$ & $\mathrm{B}$ & $\mathrm{C}$ & $\mathrm{D}$ & $\mathrm{E}$ & $\mathrm{F}$ \\
\hline $\mathrm{Ca}$ & 24.7 & & & 47.1 & 30.3 & 15.1 \\
$\mathrm{Cu}$ & 1,330 & 14 & & 6,400 & 28 & \\
$\mathrm{~K}$ & 7.0 & 6.4 & 5.5 & 8.0 & 8.1 & 5.7 \\
$\mathrm{Na}$ & 6.4 & & & 8.4 & 9.1 & 15.7 \\
$\mathrm{Zn}$ & & & 11.5 & 12.6 & 11.4 & 1,650 \\
\hline
\end{tabular}

$A 0.01 \mathrm{M} \mathrm{HCl}, B \mathrm{H}_{2} \mathrm{O}, C \mathrm{H}_{2} \mathrm{O}, D 0.01 \mathrm{M} \mathrm{HCl}, E 20 \% \mathrm{HCHO}$, $F 0.5 \mathrm{M} \mathrm{H}_{2} \mathrm{SO}_{4}$. ELAN ICP-MS DRCII by Perkin-Elmer

registered. This details the intensity of the corrosion processes in the enamel-metal object in an organic solvent. In addition to the enamel corrosion mechanisms the metal material's deterioration was also observed.

\subsection{Raman spectroscopy}

After analyzing the results of SEM and having matched the corresponding Raman spectra for the obtained results, it can be argued that in the case of sample B cuprite (copper (I) oxide), corrosion products on the surface of the sample were found. This mineral forms isometric crystals with a needle pattern octahedron, confirmed by the SEM observation (Fig. 4). In addition to this, peaks indicate the presence of copper (II) - $\mathrm{CuO}$, or 'tenorite' - a mineral which is extremely rare in nature. The last identified product for the sample $\mathrm{B}$ was malachite- $-\mathrm{Cu}_{2} \mathrm{CO}_{3}(\mathrm{OH})_{2}$. It belongs to the group of carbonates and is widespread. It occurs in dense clusters to form dark brown coatings and raids, and also confirmed the SEM observations.

For sample D, only one measurement of the green powder was performed because the corrosion product was on the whole surface of the sample and the solution. The products that have been identified are: atacamite- $-\mathrm{Cu}_{2}$ $\mathrm{Cl}(\mathrm{OH})_{3}$ and eriochalcite- $\mathrm{CuCl}_{2} \cdot 2 \mathrm{H}_{2} \mathrm{O}$. The first one belongs to the group of halides. It is perfectly pointed; the crystals are green, have a diamond shine and crystallized in a rhombic pattern. This mineral occurs in clusters, is needle-like and is clearly visible under the scanning electron microscope (Fig. 4). This was shown to be an eriochalcite crystallized ortho-rhombic system, a rare mineral which has a greenish-blue color.

Raman spectra measurements of the metal substrate for the sample $\mathrm{E}$ found copper oxide $\mathrm{CuO}$-tenorite and malachite $-\mathrm{Cu}_{2} \mathrm{CO}_{3}(\mathrm{OH})_{2}$. Measurements closer to the enamel showed that at around $300 \mathrm{~cm}^{-1}$ a peak is presented, which is characteristic for hydrated glass. In addition, the peaks for the $\mathrm{Si}-\mathrm{O}$ bonding and the area of the silica are evident. A peak at 2,900 $\mathrm{cm}^{-1}$ was recorded, providing evidence of the presence of $\mathrm{K}^{+} \mathrm{HCOO}^{-}$. This is very important and indicates the occurrence of a reaction between formaldehyde and potassium ions leached from the glass. The spectrum shows polymerization of enamel which has confirmed glass aging [20]. Modifications are confirmed by the presence of peaks in the area of $1,500 \mathrm{~cm}^{-1}$. Raman spectrum of organic compounds is very complex, for example creating formates active in the area of $2,000-3,000 \mathrm{~cm}^{-1}$.

The analyses for sample $\mathrm{F}$ showed the presence of malachite- $\mathrm{Cu}_{2} \mathrm{CO}_{3}(\mathrm{OH})_{2}$ and copper oxide CuO-tenorite. Malachite is a mineral, which often finds itself contaminating silicon and calcium. This was confirmed by SEM analysis, which showed the presence of these elements. The values of the peaks and the shape of the Raman spectrum indicate the presence of zinc oxide (mineral form: zincite) and hydrated zinc sulfate $\mathrm{ZnSO}_{4} \cdot 6 \mathrm{H}_{2} \mathrm{O}$ (mineral form: biankit). In addition to this, several peaks were found which would indicate the presence of gypsum $\mathrm{CaSO}_{4-}$ $2 \mathrm{H}_{2} \mathrm{O}$. A microscopic (SEM) picture provided proof of this result. 


\section{Conclusion}

Macroscopic and microscopic observations provided information about the intensity of the processes. In an environment of hydrochloric acid $(0.1$ and $0.01 \mathrm{M} \mathrm{HCl})$ applied to samples: A and D, it is clear that the band made of brass and copper is not resistant and undergoes a process of dissolving, forming deposits on the surface of glass, on the metal and between the materials. In addition, tarnished glass was observed, especially in samples B and C, which were immersed in water. As a result of corrosion of the enamel in formaldehyde, clear cracks appeared on the blue enamel with small white deposits between those materials.

A sensor sample of Limoges enamel on copper (sample E) has distinct corrosive changes. Enamel applied on the metal substrate disconnected after 76 days of induced corrosion. This indicates how intense the effects of formaldehyde are on the object, glass-copper. As a result, the appearance of cracks and holes was rapid at the edge of a superficial layer of enamel as a result of the detachment of vitreous material (enamel). Another way to facilitate the penetration can lead to a way for the heat treatment of the glass enamel. In the case of poorly chosen temperature parameters, weak adhesion strength between enamel and metal could become apparent, which will promote more rapid penetration of corrosive media upon the glass object. Equally important in the acceleration of this phenomenon is the enamel's preparation and careful selection of the composition-including the use of a specific surface material. In this case, copperplate. The results illustrate as to how damaging the presence of organic matter can be on stored glass-metal objects. Unfortunately, they are still used in museum display cases of fiberboard, which will inevitably lead to this kind of corrosive mechanism.

The study identified an aggressive environment affecting the glass sensor replicating an eighteenth century glasstype beaker and fifteenth century enamel from Limoges, in combination with various metals. As for the glass sensors, most chemical and physical changes occur during their storage in an aqueous medium. This is explained by the occurrence of hydration, hydrolysis and leaching. Glass becomes slightly matted with its surface covered with silica gel; thereby acting as a catalyst by activating the reactions with the environment. Formaldehyde causes some structural defects in glass and the $\mathrm{COOH}^{-}$ions easily combine with leached potassium ions $\mathrm{K}^{+}$, forming a crystallized deposit on the surface of the glass.

Storing a variety of connected materials is important when remembering to create the optimal conditions for the two constituent materials. The parameters for storing glass objects connected of two (or more) materials must be very well matched to avoid developing corrosion on one or two components. Usually the weakest began the deterioration process. Glass does not like to be kept in or near moisture, and the metal is very sensitive to chlorides. Organic material is harmful to both types of materials and sulfates cause the formation of deposits on the surface (such as gypsum). The study also showed the effect of an elevated temperature, which initiates a chemical degradation process.

Acknowledgments Sincere thanks to Prof. Marco Grotti from the University of Genoa for the implementation of LA ICP analysis for solutions. We also would like to extend our gratitude to Serena Compodonico, University of Genoa for the performance of Raman spectroscopy for samples. The research was financed by the AGH University of Science and Technology statutory grants no 11.11.140.319 and 11.11.160.365.

Open Access This article is distributed under the terms of the Creative Commons Attribution License which permits any use, distribution, and reproduction in any medium, provided the original author(s) and the source are credited.

\section{References}

1. E. Greiner-Wronowa, L. Stoch, Influence of environment on surface of the ancient glasses. J. Non Cryst. Solids 196, 118-127 (1996)

2. M. Del Monte, in The cultural heritage: causes of damage, ed by N.S. Baer, C. Sabbioni, A.I. Sors. I Science, Technology, and European cultural heritage: proceedings of the European Symposium, Bologna, June 13-16, Butterworth-Heinemann Publishers, Italy, 1989, 67-77

3. D. Camuffo, Acid rain and deterioration of monuments: how old is the phenomenon? Atmos. Environ. Part B Urban Atmos. 26(2), 241-247 (1992)

4. E. Speel, H. Bronk, Enamel Painting. Materials and Recipes in Europe from c. 1500 to c. 1920, Berliner Beitrage zur Archeometrie 2001; 18: 43-100

5. I. Biron, M. Verità, Analytical investigation on Renaissance Venetian enamelled glasses from the Louvre collections. J. Arch. Sci. 39(8), 2706-2713 (2012)

6. O. Schalm, V. Van der Linden, P. Frederickx, S. Luyten, G. Van der Snickt, J. Caen, D. Schryvers, K. Janssens, E. Cornelis, D. Van Dyck, M. Schreiner, Enamels in stained glass windows: preparation, chemical composition, microstructure and causes of deterioration. Spectrochim. Acta. Part B 64(8), 812-820 (2009)

7. D. G. Bonne, I. Biron, P. Trocellier, The origin of the degradation of painted enamels, in: Glass, Ceramics and Related Materials Interim Meeting of the ICOM-CC Working Group, Vantaa, September 13-16, Finland, 1998, n.p

8. L.L. Hench, Characterization of glass corrosion and durability. J. Non Cryst. Solids 19, 27-39 (1975)

9. S. Greiff, J. Schuster, Technological study of enamelling on roman glass: the nature of opacifying, decolourizing and fining agents used with the glass beakers from Lubsow (Lubieszewo, Poland). J. Cult. Herit. 9, 27-32 (2008)

10. P. Colomban, On-site Raman identification and dating of ancient glasses: a review of procedures and tools. J. Cult. Herit. 9, 55-60 (2008)

11. D. Neff, P. Dillmann, L. Bellot-Gurlet, G. Beranger, Corrosion of iron archeological artefacts in soil: characterization of the corrosion system. Corros. Sci. 47(2), 515-535 (2005) 
12. A. Giumlia-Mair, On surface analysis and archeometallurgy. Nucl. Instrum. Methods Phys. Res. Sect. B 239(1-2), 35-43 (2005)

13. M. Vilarigues, P. Redol, A. Machado, P.A. Rodrigues, L.C. Alves, R.C. Silva, Corrosion of 15 th and early 16th century stained glass from the monastery of Batalha studied with external ion beam. Mater. Charact. 62, 211-217 (2011)

14. J. Kunicki-Goldfinger, Preventive conservation strategy for glass collections. Identification of glass objects susceptible to crizzling, in: Cultural heritage research: a Pan-European challenge. Proceedings of the 5th EC conference, Kraków, May 16-18, ICSC, Poland, 2002, 301-304

15. P. Ricciardi, P. Colomban, A. Tournié, M. Macchiarola, N. Ayed, A non-invasive study of Raman Age mosaic glass tesserae by means of Raman spectroscopy. J. Arch. Sci. 36(11), 2551-2559 (2009)
16. M. Melcher, R. Wiesinger, M. Schreiner, Degradation of glass artifacts: application of modern surface analytical techniques. Am. Chem. Soc. Public 43(6), 916-926 (2010)

17. E. Greiner-Wronowa, C. Paluszkiewicz, L. Stoch, Applying FTIR spectroscopy in the study of archeometric sensor glasses. J. Molec. Struct. 511-512, 199-204 (1999)

18. A. Adriaens, M.G. Dowsett, Electron microscopy and its role in cultural heritage studies. Compr. Anal. Chem. 42, 73-128 (2004)

19. M.R. Pinasco, M.G. Ienco, P. Piccardo, G. Pellati, E. Stagno, Metallographic approach to the investigation of metallic archaeological objects. Anal. Chim. 7, 553-574 (2007)

20. C. Robinet, L. Coupry, K. Eremin, C. Hall, Raman investigation of the structural changes during alteration of historic glasses by organic pollutants. J. Ram. Spectrosc. 37, 1278-1286 (2006) 